\title{
Capital social e clientelismo em comunidades extrativistas no sul do Amapá - Amazônia brasileira
}

\section{Social capital and patronage in extractive communities in the south of the Amapá state - Brazilian Amazon}

Adalberto Carvalho Ribeiro - Doutor em Desenvolvimento Socioambiental, pelo Núcleo de Altos Estudos Amazônicos da Universidade Federal do Pará (NAEA/UFPA). Professor do Departamento de Educação da Universidade Federal do Amapá (UNIFAP). E-mail: adalb.cr@gmail.com.

Marco Antonio Chagas - Doutor em Desenvolvimento Socioambiental, pelo Núcleo de Altos Estudos Amazônicos da Universidade Federal do Pará (NAEA/UFPA). Professor do Departamento de Meio Ambiente e Desenvolvimento e do Programa de Pós-Graduação em Desenvolvimento Regional da Universidade Federal do Amapá (UNIFAP). E-mail: marco.chagas@uol.com.br.

Elimar Pinheiro do Nascimento - Doutor em Sociologia, pela Universidade Paris V (Rene Descartes). Professor do Programa de Pós-Graduação em Desenvolvimento Sustentável do Centro de Desenvolvimento Sustentável da Universidade de Brasília (UnB). E-mail: elimarcds@gmail.com.

\section{Resumo}

O artigo analisa a dinâmica do capital social e do clientelismo em comunidades extrativistas no sul do estado do Amapá, especificadamente no Assentamento Agroextrativista do Maracá, na Reserva Extrativista do Rio Cajari e na Reserva de Desenvolvimento Sustentável do Rio Iratapuru. A capacidade organizacional dessas comunidades, elevadas há pouco tempo ao status de populações tradicionais, ainda gera controvérsia entre pesquisadores. Essas comunidades preservam formas coletivas de solucionar problemas, contudo, quando as ações são mais complexas expressam maiores dificuldades em seguir adiante. Os resultados apontam capacidade organizacional e existência de capital social comunitário para resolver determinadas questões mais simples. Porém, existem evidências contundentes de interesses clientelistas nas unidades estudadas, com variações que se manifestam por meio de relações comerciais, formas de aviamento e pela presença de agentes políticos partidários, estes muitas vezes representados pela própria liderança comunitária.

\section{Palavras-chave}

Capital Social. Clientelismo. Comunidades Extrativistas. Sul do Amapá.

\begin{abstract}
This paper analyses the dynamics of social capital and patronage in extractive communities in the south of the Amapá state, particularly in the Agro-Extractive Settlement of Maracá, in the Extractive Reserve of the Cajari River and in the Sustainable Development Reserve of the Iratapuru River. The organizational capacity of these communities, recently recognized as traditional populations, still creates controversy among researchers. The communities preserve collective problem-solving mechanisms, but these face difficulties when dealing with more complex challenges. The findings indicate organizational capacity and the existence of communitarian social capital to solve some simple tasks. However, there is strong evidence of clientelistic interests in the studied communities, manifested by different ways in trade relations, in the practice of aviamento - a semi-slavery system of debt peonage - and in the presence of partisan political agents, these frequently represented by the communitarian leadership itself.
\end{abstract}

\section{Keywords}

Social Capital. Patronage. Extractive Communities. South of the Amapá State. 


\section{INTRODUÇÃO}

A região sul do estado do Amapá, na fronteira com o Pará, pode ser considerada um verdadeiro laboratório para pesquisa socioambiental. A história da apropriação de terras do Projeto Jari e os consequentes conflitos pela reconfiguração do espaço como resultado das lutas de comunidades extrativistas para criação de unidades territoriais voltadas para o uso sustentável constituem elementos que motivam pesquisas interdisciplinares.

Nesse cenário de conflitos permanentes, de lutas por direitos cognitivos e por políticas públicas, os governos, federal e do Amapá, entre as décadas de 1980 e 1990, criaram unidades territoriais de uso especial, especificamente o Projeto de Assentamento Agroextrativista do Maracá (PAA Maracá), a Reserva Extrativista do Rio Cajari (RESEX Rio Cajari) e a Reserva de Desenvolvimento Sustentável do Iratapuru (RDS do Rio Iratapuru) (Figura 1).

Figura 1 - Localização das unidades territoriais de uso especial do sul do Amapá

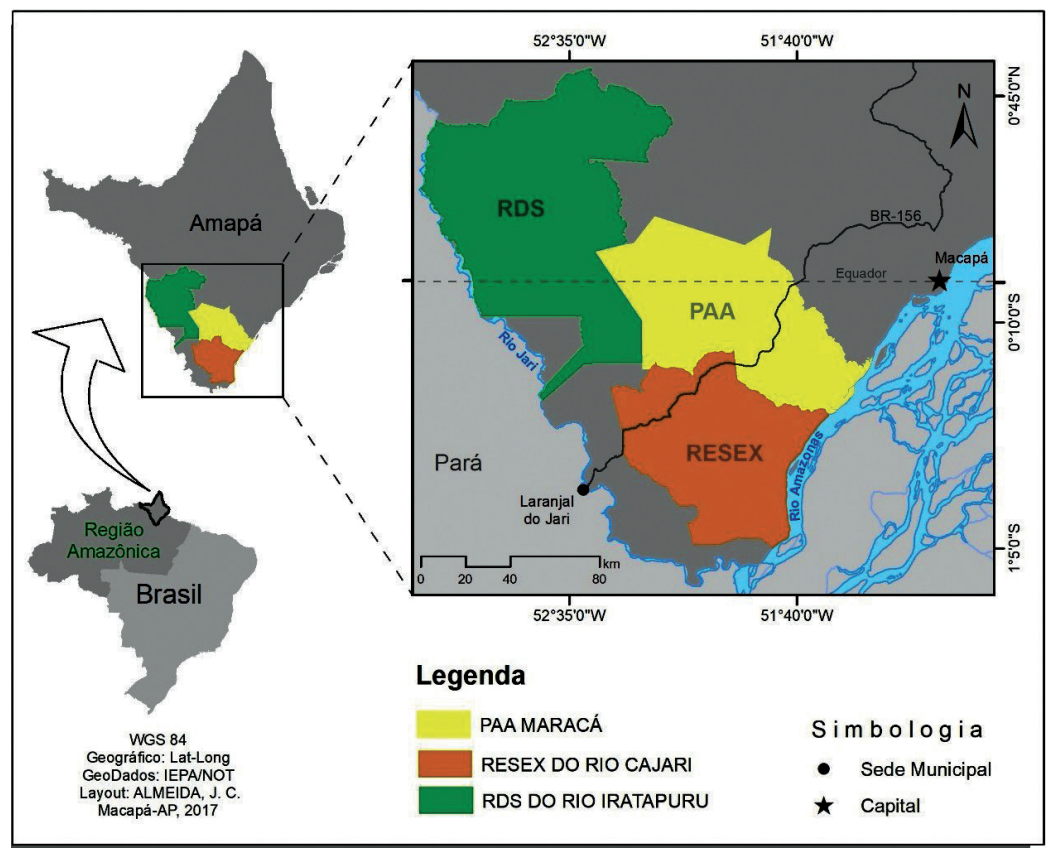

Fonte: Elaborado pelo geógrafo Jodson Cardoso de Almeida

Estas unidades territoriais foram criadas em um momento histórico de intensos debates e embates do socioambientalismo na Amazônia, com destaque para o movimento dos seringueiros liderado por Chico Mendes e apoiado por uma rede de solidariedade global. Naqueles tempos, os trabalhadores rurais também 
se organizaram no Amapá e se fizeram presentes por meio de conquistas em favor do direito de viver em áreas fora do sistema capitalista dominante na região.

Na década de 1980, com a ascensão do movimento socioambiental na Amazônia, verificou-se, e a sociedade se deu conta, da capacidade de organização e de luta de comunidades que até então eram invisibilizadas pela negação de alternativas políticas e de direitos, principalmente à terra, como os pequenos agricultores, ribeirinhos, seringueiros, castanheiros e outros grupos sociais.

Por outro lado, são flagrantes nesses movimentos, - mas não somente nesses -, formas de relações sociais que apontam para atuação de redes de interesses comerciais (aviamento) ou políticos eleitorais (formas de cooptação de lideranças) que oportunizam pesquisas interdisciplinares, com interações teóricas que, no presente estudo, se apropriam das categorias "capital social e clientelismo", com contributos epistêmicos de Pierre Bourdieu, James Coleman e John Durston, entre outros autores, para explicar como se movimentam os principais membros de comunidades rurais na Amazônia.

Neste contexto, em que a capacidade organizacional dessas comunidades, elevadas em pouco tempo ao status de populações tradicionais, ainda gera controvérsia entre os pesquisadores, este trabalho tem como objetivo principal contribuir para a discussão sobre a dinâmica de capital social e das relações clientelistas em comunidades rurais da região sul do estado do Amapá, especificamente nas unidades territoriais PAA Maracá, RESEX Rio Cajari e RDS do Rio Iratapuru.

A pesquisa de campo foi realizada em 2008 e supervisionada nos anos subsequentes, até 2017, de modo a validar os achados de campo em relação ao capital social e ao clientelismo nas comunidades estudadas. Em termos metodológicos, foram utilizadas abordagens etnográficas e outras qualitativas, destacando-se técnicas como observação in loco, escuta profunda e autoreflexividade, conversas informais e entrevistas abertas com lideranças locais e com membros das comunidades selecionados aleatoriamente na medida do avanço da confiabilidade e da reciprocidade da pesquisa.

As seguintes comunidades foram visitadas: Vila Maracá e Vila Maruím (localizadas no PAA Maracá); Sororoca, Santa Clara, Água Branca do Cajarí, Marinho, Açaizal e Martins (localizadas na RESEX do Rio Cajari) e; São Francisco do Iratapuru, localizada na RDS do Rio Iratapuru. As inserções eram periódicas e intercaladas, de modo que se residia, em média, 10 (dez) dias em cada comunidade, com exceção da RESEX do Rio Cajari, devido a que nesta unidade as comunidades não são tão dispersas. Foi possível, desse modo, firmar uma base na comunidade de Santa Clara e visitar as demais durante o período de pesquisa reservado à RESEX do Rio Cajari. 
A recorrência das visitas permitiu interações significativas e criação de laços de confiança entre pesquisadores, comunidades e lideranças. Após o ano de 2008, outras pesquisas se realizaram nas unidades, ainda que com escopos diferentes, todavia, permitindo observações, conversas informais com lideranças consolidadas, jovens e outros membros das comunidades.

Passada quase uma década, pode-se dizer que o quadro pouco se modificou. A rede comercial propriamente dita ainda se estrutura com os mesmo mecanismos de 2008, do mesmo modo que a rede vinculada aos interesses políticos, que até se radicalizou ainda mais com o fortalecimento dos laços entre políticos com mandato, lideranças antigas, novas lideranças e outras formas de apadrinhamento diversificadas.

O extrativismo da castanha-do-brasil e a pequena atividade agropecuária constituem os principais modos de vida das comunidades do sul do Amapá, com histórico de conhecimento tradicional associado às culturas da espécie e as práticas de manejo associadas. Nesse sentido, o termo agroextrativismo, mais abrangente, representa a diversidade produtiva das comunidades, que não se restringe somente à coleta da castanha-do-brasil. Entretanto, o grupo delimitado para a presente pesquisa é aquele vinculado diretamente às atividades extrativistas da castanha-do-brasil, conhecidos regionalmente como "castanheiros".

\section{UNIDADES TERRITORIAIS DE USO ESPECIAL AGROEXTRA- TIVISTA NO SUL DO AMAPÁ}

As unidades territoriais estudadas estão localizadas no sul do estado Amapá, fronteira com o Pará, na Amazônia brasileira, em terras que constituem o vale do rio Jari, onde no começo do século XX, o coronel José Júlio de Andrade constituiu o "maior latifúndio do planeta". Estima-se que três milhões de hectares foram incorporados ao domínio do coronel, onde era coletado castanha-dobrasil para exportação, mas também borracha, copaíba, além de criação de gado e da extração de ouro superficial ou primário.

A partir de 1967, a região passou a abrigar um megaempreendimento agroindustrial liderado pelo norte-americano Daniel Ludwig (Projeto Jari). A finalidade do projeto era a produção de celulose, mas outras iniciativas econômicas foram desenvolvidas com o intuito de transformar a região no maior celeiro de produção de alimentos do planeta. A referida ocupação de extrativismo empresarial e posteriormente de projeto agroindustrial intensivo de capital desencadeou uma série de conflitos com comunidades que ocuparam a região de maneira esparsa e adotaram como modo de sobrevivência o extrativismo, sobretudo da castanha-do-brasil. 
Em relação à organização das comunidades, Pedro Ramos de Souza ${ }^{1}$ faz referência ao ano de 1986, quando aconteceu a primeira viagem do presidente do Sindicato dos Trabalhadores Rurais do Amapá (SINTRA) para discutir a organização sindical dos moradores da região e os conflitos fundiários existentes entre estes e o Projeto Jari. Nessa época havia um grupo de seguranças armados do Projeto Jari que oprimia com violência os moradores de forma a não permitir a construção de benfeitorias que colocassem em risco a propriedade da Jari (FILOCREÃO, 2007, p. 266).

O Assentamento Agroextrativista Maracá, a Reserva Extrativista do Rio Cajari e a Reserva de Desenvolvimento Sustentável do Rio Iratapuru surgem como resultado da luta de comunidades rurais extrativistas do Amapá pela garantia de uma justa distribuição de terras e do uso sustentável dos recursos naturais no âmbito do reconhecimento de modalidades de ocupação vinculadas a políticas federais, tanto da reforma agrária quanto da conservação da natureza (Figura 2).

\subsection{PROJETO DE ASSENTAMENTO AGROEXTRATIVISTA MARACÁ}

Em 1987, o Instituto Nacional de Colonização e Reforma Agrária (INCRA), após pressão política do Conselho Nacional dos Seringueiros (CNS), reconheceu no âmbito da Política Nacional de Reforma Agrária a modalidade de Projeto de Assentamento Agroextrativista (PAA), criando no Amapá, no ano seguinte, o PAA Maracá com uma área unificada em 1997 de 569.208 hectares:

O primeiro órgão regional a se declarar, publicamente, favorável a essa modalidade de reforma agrária (PAA) e decidir apoiar todas as iniciativas necessárias para criar o primeiro projeto foi a Superintendência do INCRA no Amapá, naquela ocasião administrada por Guairacá Nunes. Assim que foi assinada a Portaria criando o PAA, ele encaminhou uma proposta preliminar visando à criação de três projetos na bacia do rio Maracá, no sul do estado. Com apoio estadual e federal tiveram início os estudos e discussões com as comunidades, visando à identificação das áreas extrativas do sul do Amapá (ALLEGRETTTI, 2002, p. 583).

O perfil socioeconômico e cultural dos moradores do PAA Maracá se enquadra na categoria do típico campesinato caboclo da Amazônia, conforme categorização de Costa (2012). São predominantemente de origem amapaense (90\%), constituindo uma população de assentados estimada em 1.000 famílias,

Liderança amazônica do movimento de trabalhadores rurais, com atuação junto às comunidades de extrativistas de castanha-do-brasil do sul do Amapá. Teve participação ativa na luta de Chico Mendes, com quem compartilhou vários momentos em prol da organização dos trabalhadores da floresta. Vive no Amapá e continua ativista. 
distribuídas pelas diversas comunidades que ocupam o vale do rio Maracá e entorno. A maior concentração populacional é na comunidade localizada às margens da BR-156, na Vila Maracá (FILOCREÃO, 2007).

A composição da renda das unidades familiares agroextrativistas se baseia em rendas advindas das atividades agrícolas do cultivo da mandioca, milho, banana e alguns outros tubérculos e frutos, ao passo que as atividades extrativistas estão ligadas a madeira, palmito, frutos do açaí e castanha-do-brasil.

\subsection{RESERVA EXTRATIVISTA DO RIO CAJARI}

Criada em 1990, com uma área de 501.771 hectares, a Reserva Extrativista do Rio Cajari teve sua origem vinculada à atuação do Instituto de Estudos Amazônicos e Ambientais (IEA), liderado pela antropóloga Mary Allegretti e do Conselho Nacional dos Seringueiros, tendo à frente o líder extrativista Pedro Ramos de Souza (CHAGAS; RABELO, 2015, p. 220-221).

Segundo Filocreão (2014, p. 147), o maior mérito dos beneficiários com a criação da RESEX do Rio Cajari foi desarticular o secular aviamento a que os castanheiros eram submetidos pelos atravessadores e construir relações econômicas de desenvolvimento sustentável local. Estima-se que existam 1.200 famílias morando na RESEX. A maior comunidade é Água Branca do Cajari, localizada às margens da BR-156 e onde se concentra algum serviço público de saúde e educação.

\subsection{RESERVA DE DESENVOLVIMENTO SUSTENTÁVEL DO RIO IRATAPURU}

A RDS do Rio Iratapuru é uma unidade de conservação estadual criada em 1997 com uma área de 806.184 e inspirada no Programa de Desenvolvimento Sustentável do Amapá (PDSA), implementado na primeira gestão do governador do Amapá, João Alberto Capiberibe (1995-1998). É a segunda do país nessa categoria e se destina à proteção dos recursos naturais e ao desenvolvimento de práticas produtivas sustentáveis, com destaque para o extrativismo e beneficiamento da castanha-do-brasil.

A única comunidade existente na RDS é a Vila de São Francisco, localizada na foz do rio Iratapuru, onde moram 35 famílias. O traço marcante da formação socioeconômica e cultural da comunidade é o fato de ter se mantido, por muito mais tempo que as outras comunidades estudadas, fora das ofertas dos serviços básicos sociais, como educação e saúde. 
Essa comunidade é marcada não somente pelo isolamento geográfico, como também por permanecer por mais tempo vivendo tipicamente como famílias ribeirinhas, separadas umas das outras por algumas horas de distância, às margens do rio. Esta característica cultural pode ter forjado nas famílias do rio Iratapuru, de modo mais fecundo, o caráter do individualismo voltado para a empresa doméstica, próprio da formação do caboclo da Amazônia.

Por ser tratar de uma espécie "vitrine do PDSA", as famílias residentes na Vila São Francisco do Rio Iratapuru passaram por profundas mudanças e experimentaram formas inovadoras de convivência social, de empreendimento econômico e, consequentemente, de influências externas. Pode-se dizer que essa comunidade conheceu, em grau maior que as demais comunidades estudadas, saltos evolutivos abruptos, descompassados e desequilibrados a partir de reivindicações comunitárias, mas também de projetos exógenos, elaborados em nome de políticas públicas e de programas de cooperação internacional filiados às teses do desenvolvimento sustentável.

Figura 2 - Extrativistas de castanha do sul do Amapá (1) Castanheiro; (2) Transporte de castanha com uso de trator; (3) Reunião dos castanheiros; (4) Representação política
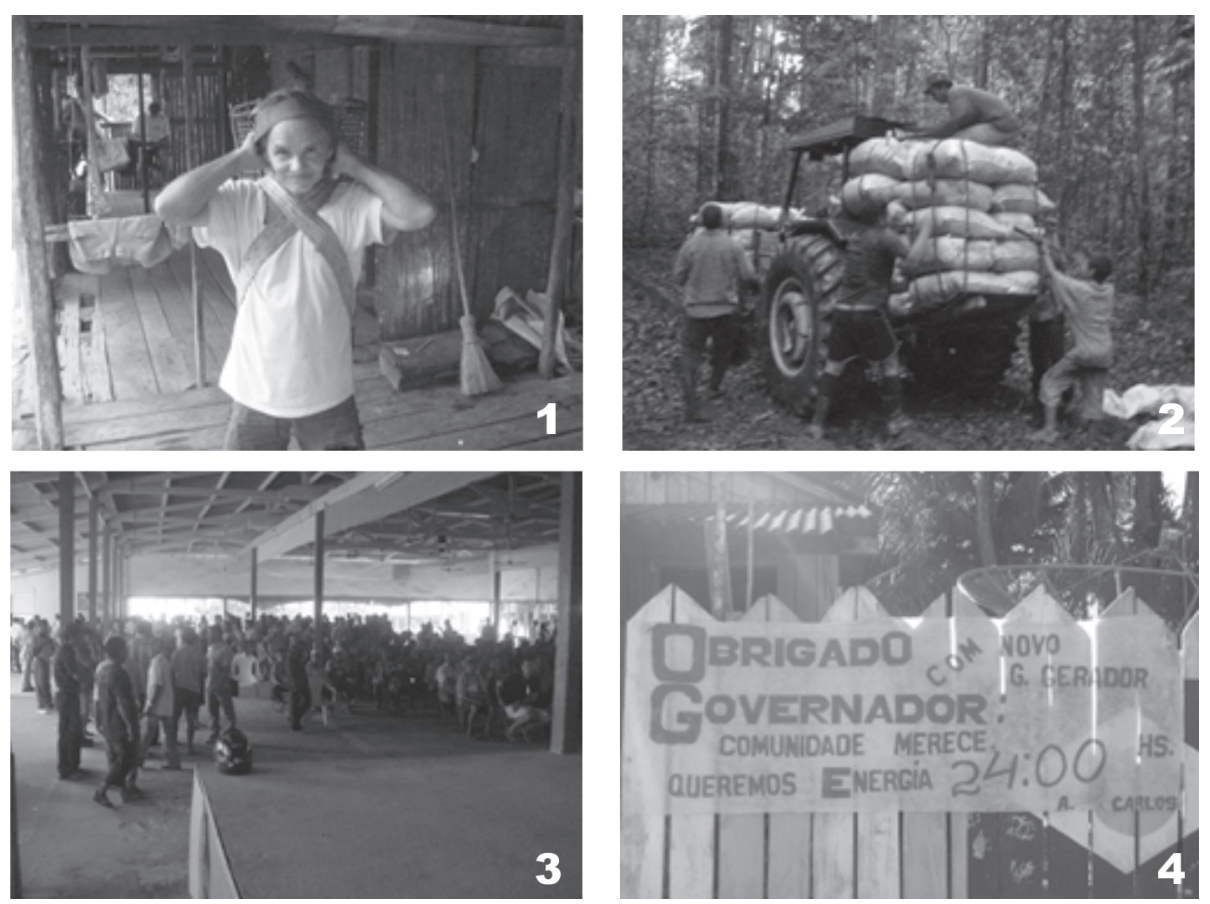

Fonte: fotos dos autores 


\section{CAPITAL SOCIAL COMUNITÁRIO E CLIENTELISMO: UMA RELAÇÃO MAL RESOLVIDA}

Capital social é uma teoria? Para alguns autores o termo não aporta suficientes elementos novos para que seja considerado um marco teórico; outros consideram tratar-se de um conceito sensibilizador que chama atenção para a importância da sociabilidade, com variações autorais que entendem haver um conjunto de hipóteses que pugnam por um "paradigma emergente", ainda que incipiente, rico em conceitos correspondentes a realidades sociais e altamente relevantes para o desenho de programas que possam prover a participação cívica e a superação da pobreza (ESPINOZA, 1998; PORTES, 2000; DURSTON, 2000, 2002, 2007).

As fontes de capital social estão nas normas e em redes de intercâmbio recíproco e solidário. As normas são partes de certas culturas e se transmitem de geração em geração, principalmente por meio da socialização no interior das famílias. As redes de intercâmbio, por outro lado, se baseiam na confiança que surge de laços de parentesco, vizinhança, amizade e sentimento de pertencimento a um mesmo grupo étnico. Portanto, capital social:

el contenido de ciertas relaciones y estructuras sociales, es decir, las actitudes de confianza que se dan en combinación con conductas de reciprocidad y cooperacíon. Ello constituye un capital en el sentido de que proporciona mayores beneficios a quienes establecen este tipo particular de relaciones y que puede ser acumulado (DURSTON, 2002, p. 15).

Capital social é um atributo de comunidades? Bourdieu (1996) e Coleman (1988) partilham da ideia de capital social como atributo de grupos sociais, coletividades e comunidades, fomentado por interações em redes de acesso a recursos e oportunidades. Portanto, na intercessão das diferentes matizes autorais, capital social associa-se às normas e instituições orientadas à promoção da confiança, da reciprocidade e da cooperação nas relações comunitárias.

Em tese, o capital social pode beneficiar tanto indivíduos quanto comunidades. Entretanto, a natureza das relações não é uma soma de interações entre indivíduos que responde às decisões de interesse pessoal, e sim sistemas complexos que surgem da coevolução dessas decisões e interações.

Entretanto, dois problemas do marco conceitual do capital social continuam presentes: i) detectar os princípios do funcionamento dos sistemas sociais e; ii) entender como se dá a interface das ações individuais com sistemas que delas emergem. Para Durston (2000), a teoria da complexidade de Edgar Morin oferece um bom aporte para o entendimento do capital social comunitário, 
enquanto a teoria antropológica da organização social pode esclarecer sobre ações individuais emergindo de sistemas específicos.

Não se pode negligenciar que tanto o capital social individual como o comunitário são partes de uma mesma cultura compartilhada e internalizada pelos indivíduos que compõem uma comunidade. O capital social comunitário é a institucionalidade formal e informal que integra as normas culturais de confiança entre indivíduos, com práticas de cooperação entre os membros de um determinado sistema social. Mecanismos precursores do capital social comunitário abarcam expectativas de reciprocidade dos indivíduos.

Os dois conceitos (capital social individual e capital social comunitário) são igualmente válidos e se complementam, embora sejam heuristicamente distintos. O capital social individual se manifesta principalmente nas relações sociais, com vínculos de confiança e reciprocidade e se estende por intermédio de redes egocentradas (pessoais). O comunitário, ao contrário, se expressa em instituições complexas, com laços de cooperação e gestão.

As instituições são entendidas como sistemas que tendem a produzir satisfações para as necessidades sentidas de todo um grupo de pessoas ou uma parte do grupo. Produz também efeitos que retroalimentam e reforçam sua própria viabilidade como sistema complexo baseado em múltiplos agentes. Geram normas, estas, por sua vez, orientam o comportamento do indivíduo para fortalecer a instituição como sistema:

Cómo emergen las instituiciones del capital social comunitario? La existencia del capital social es compatible con, y de hecho surge de, las decisiones racionales de los indivíduos. Esto es asi porque hay beneficios en poder gestionar recursos comunes en forma coherente y en renunciar al control personal recursos proprios, para que haya autoridad, normas, y un contexto institucional para enfrentar problemas y oprtunidades comunes (DURSTON, 2000, p. 23).

A institucionalidade do capital social comunitário, ainda segundo Durston (2000), pode surgir por meio de pelo menos quatro processos diferentes: i) coevolução de estratégias de pessoas; ii) decisões racionais e conscientes dos indivíduos que compõem uma comunidade; iii) socialização de normas relevantes de uma cultura na infância e; iv) induzida por uma agência externa.

A presença de capital social comunitário não é garantia de que resultados positivos se efetivem, isto porque sua existência depende de um conjunto de outras condições favoráveis. Por outro lado, nem sempre se pode tomar a presença de benefícios públicos como prova da presença desse recurso social, mas, geralmente, a maioria dos benefícios públicos ou mesmo privados (no 
âmbito da família, por exemplo) ocorrem em estruturas que estão ligadas à existência de relações e instituições do capital social comunitário.

Quando se leva em conta, por exemplo, que as culturas resultam de aprendizagens, de comportamentos dos quais se esperam consequências benéficas, é claro que as normas e as relações que constituem o capital social não existem de forma independente dos efeitos esperados, isto é, de suas funções. Os comportamentos socializados são reforçados por normas dotadas de cargas emotivas e de crenças que surgem em torno de todas as regras e de todas as instituições sociais, legitimando-as e produzindo a internalização de seus valores na personalidade do indivíduo. Assim, os efeitos funcionais revelados no indivíduo ou no grupo são partes da reprodução e do fortalecimento do capital social.

As instituições, suas normas e regras, em determinadas circunstâncias, como no caso de comunidades extrativistas da Amazônia, não estão livres de efeitos de um capital social negativo. O clientelismo político que se estabelece por meio das redes, especialmente das redes de lideranças comunitárias, pode ser caracterizado como um capital social negativo, isto porque desvirtua as práticas coletivas e o desenvolvimento comunitário.

A noção de clientelismo político filia-se ao conceito de Bahia (2003, p. 273), que o define como "um fluxo de utilidades que se processa através de mecanismos de interação específicos que depende do retorno, a prazo, da lealdade da clientela." O termo lealdade é um dos aspectos centrais que explica relações de reciprocidade, ainda que baseadas em condições assimétricas.

Para Martins (1994, p. 20), o "clientelismo político de fundo oligárquico" ainda domina as relações de poder no Brasil, ou seja, o poder pessoal está enraizado e ainda é forte, confundindo as relações entre Estado e governo. O autor comenta:

O clientelismo político não desapareceu. Ao contrário, em muitas regiões do País ele se vigorou, embora mudando de forma, praticado por uma nova geração de políticos de fachada moderna [...] o oligarquismo brasileiro se apoia em algo mais amplo do que esse relacionamento (políticos e eleitores pobres) - ele se apoia na instituição da representação política como uma espécie de gargalo na relação entre a sociedade e o Estado (MARTINS, 1994, p. 29).

Em pesquisas empíricas sobre capital social em comunidades rurais na Guatemala e Chile, Durston (2000) encontrou subcateorizações de clientelismo, como o semiclientelismo. Para o autor, enquanto clientelismo se baseia em relações extremistas, autoritárias, no semiclientelismo se repudia o uso da força e a imposição de interesses pela provisão de serviços e apoio político. Entretanto, apesar da subcategorização do autor, na prática, os processos não são hierarárquicos e se mantêm como campos transitórios. 


\section{CAPITAL SOCIAL COMUNITÁRIO E CLIENTELISMO NO SUL DO AMAPÁ: QUADRO EMPÍRICO}

Os resultados da pesquisa permitiram afirmar que para um conjunto de determinadas ações específicas existe capital social comunitário significativo no sul do Amapá. Por exemplo, nas dinâmicas das redes de parentesco, vizinhança e compadrio existem fortes laços horizontais solidários que não permitem que as pessoas fiquem sem alimento ou sem teto para morar. Também para pequenos socorros emergenciais a rede comunitária funciona muito bem (RIBEIRO, 2008).

Essas práticas inseridas, ou melhor, para usar o termo de Granovetter (1985), "embebidas", na cultura camponesa do caboclo amazônico do sul do Amapá funcionam como parte dos mecanismos de reprodução e de desenvolvimento das relações sociais locais. Circulam ações de solidariedade, reciprocidade e confiança, sustentadas nos laços de consanguinidade, parentesco, vizinhança e compadrio, portanto, sobre fortes laços, mas, ao mesmo tempo "ossificados", pois, ao considerar condições estruturais e históricas, permanecem com poucas possibilidades de inovações sociais de grandes impactos, pelo menos em curto prazo.

A rede social nessas comunidades apresenta atores com papéis diferentes, muitas vezes vinculados a interesse econômico, tais como: a) representantes comunitários; b) presidentes de associações ou cooperativas; c) representantes de órgãos públicos locais, principalmente das Prefeituras; d) comerciantes; e) pequenos patrões. Estes últimos exercem funções híbridas. São compadres de muitas pessoas, bem como padrinhos de crianças ou até parentes por laços de consanguinidade. Ao mesmo tempo, são também compradores da produção da castanha-do-brasil das unidades familiares. Por todos os cinco atores perpassam mecanismos de ações clientelistas.

Os comerciantes e os pequenos patrões ${ }^{2}$ na rede comunitária muitas vezes corroboram práticas de ação coletiva. A atuação principal é na comercialização, comprando geralmente a castanha-do-brasil, vendendo gêneros alimentícios ou utensílios domésticos e financiando demandas das unidades familiares no sistema creditício.

\section{DINÂMICA DAS AÇÕES COLETIVAS NAS UNIDADES AGROEXTRATIVISTAS DO SUL DO AMAPÁ}

$\mathrm{Na}$ região dos castanhais do sul do Amapá ações coletivas têm sido instrumentos de vários grupos, comunidades e organizações rurais, para enfrentar

\footnotetext{
"Comerciante" é uma categoria diferente de pequeno patrão. São nascidos e criados na própria comunidade, chefes de unidades agroextrativistas e, portanto, mantêm uma perfeita identidade com a região e com seus parentes consanguíneos.
} 
seus problemas do dia a dia. Desde os anos de 1980, por exemplo, com um maior protagonismo da sociedade civil, muitas esperanças e possibilidades têm sido depositadas nas ações coletivas realizadas na região como parte do processo de luta pela posse da terra.

Explicar a ação coletiva na região dos castanhais do sul do Amapá, contudo, sugere considerar o processo desde a década de 1980. Dois momentos principais do comportamento coletivo das unidades agroextrativistas estudadas devem ser destacados: $\left.1^{\circ}\right)$ quando se deflagrou as ações para a emancipação fundiária na Amazônia e; $2^{\circ}$ ) as ações em curso atualmente, que se manifestam por meio de demandas de vários tipos e modalidades, destacando-se os projetos de desenvolvimento das cooperativas e associações. O primeiro pode ser caracterizado como parte do movimento socioambiental que ocorreu na região amazônica; o segundo, como ações que estão noutra conjuntura e processo social mais complexo e desafiador. Portanto, poder-se-ia dizer que o processo comunitário nos castanhais do sul do Amapá é marcado por ações coletivas de naturezas diferenciadas.

Para o primeiro fenômeno, a categoria "novos movimentos sociais" consegue explicar muitos dos aspectos que forjaram o comportamento coletivo das populações extrativistas na década de 1980. Para os fenômenos do segundo momento, a categoria "ação coletiva", no seu sentido estrito, é mais apropriada para dar conta do processo analítico.

Como referência histórica registra-se que a década de 1960 significou um importante ponto de inflexão para os estudos dos movimentos sociais e da ação coletiva (ROBLES MORALES, 2007). Nesse período houve uma renovação nos movimentos, como os formados por organizações de jovens, de gênero ou de caráter étnico, que respondiam a um padrão diferente dos movimentos até então verificados e que estavam preocupados muito mais com as dinâmicas de classes.

Ainda para Robles Morales (2007), a categoria "movimentos sociais", ancorada nas transformações das formas de manifestação de segmentos da sociedade civil, apresenta, sinteticamente, as seguintes gêneses teóricas:

- nos Estados Unidos, com o surgimento de três linhas principais de investigação: i) a teoria do comportamento coletivo, em sua versão interacionista e construtivista; ii) a teoria da mobilização de recursos e; iii) a teoria da oportunidade política.

- na Europa, com a emergência dos fundamentos da teoria dos novos movimentos sociais. É nesta categoria que se encontra o movimento socioambiental dos castanheiros e seringueiros da Amazônia. 
No entanto, novos movimentos sociais se referem a um amplo conjunto de ações coletivas que não podem ser analisadas, nem enquadradas, apenas diante das perspectivas teóricas anteriores. O movimento socioambiental na Amazônia é uma prova disso. $\mathrm{Na}$ base do arco de alianças que resultou no êxito do movimento, com o advento dos assentamentos agroextrativistas e das reservas extrativistas, encontrava-se um fundamento de cunho moral: a preservação ambiental e a melhoria de vida de populações que estavam sendo expulsas de terras que historicamente habitavam com impactos mínimos aos ecossistemas.

Em complementação, Melucci (1999) apresenta uma definição analítica de movimento social como uma forma de ação coletiva que abraça três dimensões: i) a solidariedade; ii) o conflito e; iii) a ruptura com os limites em que ocorre a ação. Neste sentido, o processo de ação coletiva dos castanheiros da Amazônia pode ser considerado como um dos novos movimentos sociais ou "movimento socioambiental".

Por outro lado, o padrão organizacional da ação coletiva contemporânea é a rede de grupos que compartilha uma cultura de movimento e uma identidade coletiva. Como os atores coletivos são "temporários", essas redes fazem e desfazem seus nós, tornando problemática sua definição como movimentos sociais. Em outros termos, o campo de ação permanece, mas seus atores não necessariamente (MELUCCI, 1999).

O fragmento acima é muito pertinente, considerando-se a região amazônica. No caso do movimento socioambiental, antes de se concretizar a demanda pelas RESEX, formou-se uma ampla rede de parceiros em torno das reivindicações dos castanheiros e seringueiros. Com o advento das áreas protegidas, muitos atores foram embora, surgindo outros e novas parcerias foram estabelecidas. Os objetivos, pelo menos em grande parte, continuam sendo a melhoria da qualidade de vida das populações extrativistas residentes nas unidades criadas.

Contudo, quando se inaugurou o segundo momento de ação coletiva, do associativismo e cooperativismo, o sucesso não se repetiu da mesma forma. Ao contrário, muitos fracassos e problemas têm sido registrados com as tentativas de projetos coletivos, principalmente aqueles vinculados à forma de empreendimentos alternativos, apesar de que não se pode falar de sua inviabilidade, como se observará adiante.

As populações extrativistas do sul do Amapá têm esse histórico. No primeiro momento experimentaram ação coletiva, onde a função do bem produtivo era muito clara para os participantes da ação. A reivindicação por terra não reclamava ações complexas, entendidas como ações que não requerem elevados índices de capital humano, nem muitas habilidades profissionais. 
Os custos para que os participantes continuassem a colaborar com a ação reivindicatória eram muito pequenos se comparados com o benefício a ser conseguido: "um pedaço de terra para viver". Conforme os entrevistados, as reuniões eram repletas de participantes e os encaminhamentos convergiam no sentido de pressionar as autoridades públicas locais e os dirigentes da Empresa Jari para negociação.

A simples participação nas reuniões da maioria dos extrativistas e a possibilidade concreta de receber um lote de terra, ou de ter reconhecida a posse da colocação, mostravam que o bem público em questão tinha uma valiosa função produtiva e patrimonial, ainda que a propriedade não se tornasse totalmente privada. Por se tratar de unidades territoriais especialmente protegidas, o domínio permanece da União (PAA Maracá e RESEX do Rio Cajari) e do estado do Amapá (RDS do Rio Iratapuru).

No segundo momento, as ações associativistas e cooperativistas revelaramse muito custosas para as populações extrativistas. Essas ações são tipicamente "ações coletivas stricto sensu", onde o alcance dos resultados, de forma geral, pode ser considerado como alta complexidade, como, por exemplo: colher, processar, comercializar e exportar a castanha-do-brasil, agregando valor, aumentando o preço e gerando renda para a comunidade.

Não obstante, quando as comunidades e suas organizações extrativistas se envolvem em demandas coletivas de caráter eminentemente público e de menor complexidade para a execução da ação, na maioria dos casos têm-se êxito, como, por exemplo: a abertura de ramais para escoamento da produção, a construção de escolas e postos de saúde, a contratação de professores para as áreas rurais, a instalação de energia elétrica e de água encanada e tratada.

À medida que cresce o grau de complexidade da ação a ser executada em relação aos padrões culturais e econômicos locais, mais fica longe a compreensão e a capacidade de execução por parte das comunidades. Isso não significa que seus membros não colaborem nos projetos associativos ou que não queiram cooperar, pois, os registros de campo, os relatórios analisados e a bibliografia consultada comprovam a participação em processos cooperativos, mesmo em condições consideráveis de dificuldades.

As reiteradas tentativas de melhoria de renda pela agregação de valor aos produtos extrativistas, em especial a castanha-do-brasil, tem se constituído em processos muito complicados e de difícil execução. Para o bem ou para o mal, essas experiências resultam em rico processo pedagógico, deixando aprendizados que apontam para pesquisas complementares, notadamente fora ou crítico do domínio conceitual do capitalismo (RIBEIRO, 2016) e sugestivamente mais próximas das epistemologias do Sul (SANTOS; MENESES, 2010). 


\section{REDE COMUNITÁRIA E INTERESSES CLIENTELISTAS: COMERCIAIS E POLÍTICO ELEITORAIS}

As principais características observadas no âmbito da dinâmica rede comercial da castanha-do-brasil na região do sul do Amapá se revestem, na atualidade, de um processo que lembra o aviamento, mas com novos comportamentos inseridos nas relações. Um conjunto de práticas socioculturais com prestações mercantis e não mercantis, de natureza diversa e multidimensional são acrescentadas e passam a compor conceitos ainda por se estabelecer.

Entre os comerciantes, pequenos patrões e as unidades familiares, se estabelece um paradoxo entre a regra e a espontaneidade, entre a liberdade e a obrigação, fundada no conceito de "dádiva agonística", isto é, a relação comercial é também "um mundo de relações simbólicas" (MAUSS, 2001).

A dádiva agonística é aquela que ocorre num ambiente onde a vida material e moral, e suas trocas, funcionam sob uma forma desinteressada e obrigatória ao mesmo tempo. No sul do Amapá esse sistema parece estar bem configurado. Os patrões locais mantêm laços contratuais, econômicos e morais com as unidades familiares das comunidades. Os patrões, fazendo as doações, os adiantamentos e socorrendo, "desinteressadamente", às emergências familiares, mas também comprando a produção da castanha-do-brasil. As famílias, em muitos casos, pedindo pequenos favores e contando com o apoio certo do "bom patrão", retribuindo com a fidelidade na venda da castanha-do-brasil. É intercâmbio e reciprocidade ao mesmo tempo.

Patrões e unidades familiares extrativistas se comportam numa relação dialética. O contrato, informal, de natureza econômica e moral, numa troca de bens simbólicos, constitui um dos principais pilares das atuais formas de (neo) aviamento. Referida relação se filia a categoria de capital simbólico desenvolvida por Pierre Bourdieu:

Em outros termos, no princípio da ação generosa, do dom inicial de uma série de trocas, não existe a intenção consciente (calculista ou não) de um indivíduo isolado, mas essa disposição do habitus que é a generosidade, é que tende, sem intenção explícita e expressa, a conservação ou ao aumento do capital simbólico. Para quem é dotado de disposições ajustadas à lógica da economia dos bens simbólicos, o comportamento generoso não é resultado de uma escolha ditada pela liberdade, de uma decisão livre efetuada após uma deliberação que contém a possibilidade de agir de outra forma; "ele aparece como a única coisa a fazer" (BOURDIEU, 1996, p. 09. grifos nossos). 
O sistema ainda pode ser complementado a partir das "estruturas elementares da reciprocidade", conforme discorre Temple (1998 apud SABOURIN, 2008a, p. 4, grifo nosso):

As estruturas elementares de reciprocidade foram sistematizadas por Temple (1998), que identifica certos dos valores humanos que produzem ou reproduzem. As estruturas de reciprocidade binária correspondem às relações de aliança (matrimônio, compadrio, redes interpessoais, etc.) e de amizade que se estabelecem entre indivíduos, famílias e grupos. A reciprocidade binária simétrica (face to face [cara a cara]) produz a amizade. A reciprocidade binária assimétrica produz o prestígio do doador (dádiva agonística, potlach).

As relações de reciprocidade que ocorrem entre os patrões e as unidades extrativistas no sul do Amapá se sustentam, portanto, tanto em bases simétricas, quando produz graus de amizade, quanto em bases assimétricas, quando o patrão adquire o prestígio pela doação que faz por ter socorrido a unidade familiar no momento difícil, adiantando algum dinheiro para a compra do uniforme escolar e de outras demandas familiares. É um tipo de jogo cujo espectro vai da solidariedade ao autointeresse. O patrão saberá diferenciar o momento exato entre a primeira e a segunda, cobrando, se necessário, o compromisso e a lealdade do extrativista ou punindo-o e deixando-o sem a sua proteção.

A relação mercantil nas unidades pesquisadas se baseia no que Godbout (1998, p. 44) (autor: referenciado) descreve como: “dá-se, recebe-se muitas vezes mais, mas a relação entre os dois (patrão e famílias) é muito mais complexa e desmonta o modelo linear da racionalidade instrumental." Esse é o mesmo entendimento de Sabourin (2004, 2008a, 2008b) quando comenta que nos sistemas econômicos de reciprocidade a prodigalidade ou a generosidade confere prestígio e fama que se tornam fontes de autoridade e de poder, de acordo com a lógica agonística da dádiva

Baseado em análises de Mauss (2001) sobre regras de interesses, as observações relacionadas às comunidades extrativistas do sul do Amapá permitem considerar que os vínculos econômicos entre patrões locais e as unidades familiares se constituem em fatos sociais totais:

Nestes fenômenos sociais "totais", como propomos chamar-lhes, exprimem-se ao mesmo tempo, e de uma só vez, todas as espécies de instituições: religiosas, jurídicas e morais - e estas políticas e familiares ao mesmo tempo: econômicas - e estas supõem formas particulares da produção e do consumo, ou antes, da prestação e da distribuição; sem contar os fenômenos estéticos a que estes factos vão dar e os fenômenos morfológicos que manifestam estas instituições (MAUSS, 2001, p. 52). 
Sob esse achado, Martins (2008, p. 31) resume a ideia de fato social total em Mauss da seguinte forma:

\begin{abstract}
Pressupõe a presença de sistemas de reciprocidades das atividades humanas, sustentados por um simbolismo generalizado em todos os planos da vida, começando com mais intensidade afetiva e menos regulação cognitiva no plano cotidiano (do indivíduo, da família, dos amigos, etc.) e se estendendo com menos intensidade afetiva e mais regulação cognitiva para as estruturas formais (da economia, da política, da religião, da ciência etc.). [...] Mauss conseguiu demonstrar que as coisas materiais ofertadas, as hospitalidades dadas e os serviços prestados são plenos de significações que, num lado, favorecem a aliança e o vínculo e, no lado contrário, a inimizade.
\end{abstract}

As evidências empíricas, no atual contexto da região dos castanhais do sul do Amapá, levam ainda a inferências de que chefes de unidades familiares extrativistas presos a compradores locais pelos laços de compadrio e formas assistencialistas de financiamento têm dificuldades de sair dessa relação. Não se pode dizer que as pessoas não tenham consciência desses laços de dependência e subserviência. Contudo, é como se recebessem um benefício no momento que pedem o adiantamento para uma demanda familiar ou para o socorro inesperado. O bom patrão também é o compadre, parente, vizinho e amigo. Comportamentos econômicos maximizadores, mas também morais e emocionais, estão compartilhados por laços de fidelidade.

Sousa (2006), em estudos no sul do Amapá, especificadamente na RESEX do Rio Cajari, identificou três escalas de relações clientelista temporais entre compradores e castanheiros: i) de 7 anos ou mais, fidelidade intensa; ii) de 3 a 5 anos, fidelidade mediana e; iii) relações de momento, sem amarras comerciais ou morais.

O direito consuetudinário com base na palavra, "de boca", como disseram as pessoas entrevistadas, é que garante as transações comerciais. Existem, assim, três grandes fundamentos que ajudam a explicar a eficiência desse sistema comercial de transação: i) o primeiro, econômico, manifesto na pobreza; ii) o segundo, moral, pelo sentimento de uma dívida que é bem acolhida pela ética dos extrativistas, pois quem não cumpre os acordos tende a ser excluído do sistema e lhe é negado às regalias dos atendimentos aos pedidos de socorro de última hora; iii) o terceiro, fundamentado no sistema comunitário de parentesco, compadrio e vizinhança, uma das chaves para explicar a moral extrativista.

Os três fundamentos citados fazem parte de um mesmo contexto cultural e, dialeticamente, misturam-se nas relações cotidianas e amalgam-se nas relações econômicas e sociais. É a existência simultânea de manifestações de capital social 
comunitário por um lado, e de um sistema comercial espoliador por outro. A conclusão é que se torna difícil quebrar regras comunitárias num contexto de relações binárias, face a face, simétricas e assimétricas, com forte controle social e que se intensifica com o tempo, conforme identificou Sousa (2006).

O exemplo do sistema comercial com a castanha-do-brasil é apenas um dentre vários outros que ocorrem nas comunidades ${ }^{3}$. As regras contratuais de mercado, objetivas, lineares e utilitaristas, ainda não conseguiram romper completamente com a tradição cultural dessas comunidades. É por isso que o sistema extrativista permite ao patrão e comprador da castanha-do-brasil, na maioria das vezes, lucrar sempre na relação comercial associada ao neo(aviamento).

Particularmente, no caso da RDS do Rio Iratapuru existem outras singularidades. Diferente das comunidades que se localizam as margens da BR156 (PAA Maracá e RESEX do Rio Cajari), o acesso à Vila São Francisco do Iratapuru é mais difícil, distante $45 \mathrm{~km}$ a montante (rio acima) da sede municipal mais próxima (Laranjal do Jari). Ainda assim, os comerciantes compradores de Laranjal do Jari mantêm duas pessoas da comunidade adquirindo o produto das unidades familiares.

$\mathrm{Na}$ RDS do Rio Iratapuru as relações com os compradores de castanha têm sido muito tensas devido aos processos inovadores implementados na comunidade, que são mais exigentes quanto aos adotados no PAA Maracá e na RESEX do Rio Cajari. É o caso da certificação das colocações (dos castanhais), em vigor desde 2004, com regras preestabelecidas e constante acompanhamento por parte da empresa certificadora.

$\mathrm{Na}$ transição tênue das relações comerciais para a política partidária, a presença de representantes de políticos (vereadores, deputados estaduais e de autoridades legislativas federais) é constante nas comunidades. A atuação se dá, principalmente, por meio de "ações sociais" e pelo fornecimento de serviços públicos - em regra, de obrigação do poder público -, como: construção de escolas, designação de professores, viabilização de postos de saúde, abertura ou melhoramento de ramais, doações de geradores de energia, fornecimento de óleo diesel etc. Essas ações têm a finalidade de cooptar votos em eleições mandatárias.

Finalmente, devem-se considerar diferentes gradações e simultaneidades entre as relações comerciais e políticas verificadas junto às comunidades extrativistas do sul do Amapá que fundamentam as análises dos processos de capital social e do clientelismo. Referidas relações não podem ser vistas, portanto, de maneira isolada e fragmentada.

\footnotetext{
Por ocasião das entrevistas, um chefe de unidade familiar agroextrativista declarou que já emprestou pequenas quantias em dinheiro a terceiros, mas nunca cobrou qualquer dívida. Explicou ele, que um dia pode precisar e espera que a pessoa lhe atenda também.
} 
Se por um lado existem relações generalizadas de confiança, cooperação e solidariedade em redes de parentesco, compadrio e vizinhança, por outro também ocorrem relações de espoliação entre o segmento comercial e as unidades de produção que se manifestam por intermédio dos agentes externos vinculados ao poder público, com práticas clientelistas que se amalgamam no local. Ainda assim, é preciso considerar que formas de empoderamento também estão ocorrendo, pois, o processo traz junto muito de aprendizagem para as comunidades.

\section{CONCLUSÕES}

Capital social e clientelismo constituíram as categorias teóricas que deram suporte a presente pesquisa junto as comunidades extrativistas no sul do Amapá e conduziram o estudo a alguns achados que aqui são sistematizados, não sem antes destacar o reconhecimento das lutas travadas pelos trabalhadores da floresta em diferentes campos cognitivos que, na maioria das vezes, constituem "campo de ausências".

São ausências que se evidenciam pela negação ao direito à terra e pela consequente invisibilidade do trabalho do castanheiro fora do sistema capitalista dominante e que, por vezes, induzem, direta e indiretamente, ao estabelecimento de relações clientelistas.

Nesse sentido, o capitalismo e o colonialismo se aproximam para cooptar a categoria "clientelismo" e se apropriar da análise teórica como se fosse a única explicação possível. No entanto, o estudo evidenciou que as relações sociais que se estabelecem nas comunidades extrativistas são também lutas sociais de resistência a essa dominação, portanto, muito mais complexas que as teóricas tradicionais e suas metodologias possam aferir.

É preciso, portanto, relativizar alguns achados da pesquisa para que se possa entender como se articulam as organizações sociais extrativistas do sul do Amapá, no tempo e nos espaços territoriais conquistados. As conclusões, então, oferecem os seguintes pontos em destaque para motivação de novos estudos interdisciplinares, ainda escassos na região sul do Amapá:

1 - O capital social identificado nas comunidades estudadas se manifesta no nível de garantias a rede básica de seguridade e de ajuda mútua para a solução de problemas do cotidiano, evidenciando certa coesão social e solidariedade. No entanto, também é possível afirmar que, ultrapassado esse estágio, quando existe concorrência e competição por recursos, sobretudo recursos púbicos que aportam nas comunidades como forma de apoio as atividades extrativistas, geradoras ou não de renda, os processos de solidariedade e ajuda mútua ficam para trás. 
2 - Em se tratando de disputas relacionadas a recursos que geram renda, devido às enormes carências materiais das unidades familiares, elas podem chegar a rivalidades familiares ou reavivá-las, num ciclo conflituoso que se manifesta nas disputas de poder e de controle das comunidades.

3 - As disputas pelas diretorias das organizações extrativistas também são exemplos de que, para estes casos, muitas vezes os processos de solidariedade e ajuda mútua ficam para trás. Nesses momentos o capital social individual acumulado pelo presidente da associação ou de seu adversário é acionado e tais disputas se revelam embebidas de práticas clientelistas com interferência de agentes externos, geralmente de algum político que tem influência local.

4 - Alguns atores, como os presidentes de associações e cooperativas, além de representantes comunitários e de prefeituras locais acumulam capital social individual devido às funções que exercem. É comum que tal acúmulo sirva aos interesses individuais, de famílias ou de grupos políticos vinculados.

5 - Em relação especificamente à rede comercial da castanha-do-brasil, só se pode falar de capital social individual do tipo negativo. Trata-se, pela parte dos compradores, de interesses econômicos, de intercâmbios, ainda que observadas práticas mercantis e não mercantis, mas sempre prevalecendo o interesse pelo lucro, assente no aviamento que se ressignifica com o tempo.

6 - Pela parte da unidade familiar extrativista, o senso comum é ter um "patrão bom", preferencialmente um compadre ou um amigo que também possa recorrer a qualquer momento em caso de necessidade. Essa relação de proximidade aumenta a segurança de que o negócio com a venda da castanha-dobrasil vai dar certo, mantendo o aviamento presente no cotidiano dos extrativistas.

7 - Os extrativistas do sul do Amapá, de modo geral, ainda não têm as habilidades e competências específicas para estabelecer relações de longa distância, que conduzam à integração de lugares e comunidades locais para espaços regionais, nacionais e globais e, de certa forma, construir parcerias que possam inovar processos comunitários de desenvolvimento local. É certo que isso tem sido feito, mas muito mais por processos eminentemente exógenos ou descendentes do que por processos comunitários espontâneos.

8 - Demandas endógenas têm ocorrido, mas para situações simples, como no caso de parcerias com o poder público e com organizações não governamentais para apoio ao escoamento da produção extrativista (aquisição de transporte, combustível etc.). Para demandas mais complexas, como o beneficiamento e a comercialização dos produtos em mercados regionais ou nacionais, as dificuldades são muito maiores. 
9 - Em meio aos comunitários, as principais lideranças, geralmente presidentes de associações ou cooperativas, têm conseguido estabelecer relações de longa distância, mas com laços fracos. No entanto, observou-se que algumas vezes essas lideranças tiram proveito das posições que ocupam na organização extrativista e tendem a se manter no posto mais tempo do que o previsto institucionalmente ou mesmo se perpetuando.

10 - Um dos problemas identificados é a ausência de estímulo à participação dos mais jovens nos processos decisórios no âmbito das diretorias, embora se tenha observado arranjos comunitários que propiciam a participação dos cooperativados e associados nas matérias pertinentes às organizações sociais, mas pouco intensivos quando se trata de formação de novas lideranças.

Em suma, a pesquisa junto às comunidades extrativistas do sul do Amapá constatou que, na maioria dos casos, a liderança comunitária responde pelo capital social e sua intensidade, negativa ou positiva. Confirmou ainda a existência de relações clientelistas com variações que se manifestam por meio de interesses comerciais, da atuação de agentes políticos partidários e de formas de (neo)aviamento, indicando um preocupante quadro de presença de estruturas de dominação que se mantém ao longo do tempo, e até se intensificaram, na proporção das ausências e das resiliências que se confrontam.

\section{REFERÊNCIAS}

ALLEGRETTI, M. H. A construção social de políticas ambientais: Chico Mendes e os movimentos seringueiros. 2002. 827f. Tese (Doutorado em Desenvolvimento Sustentável) - Centro de Desenvolvimento Sustentável, Universidade de Brasília, Brasília, 2002.

BAHIA, L. H. N. O poder do clientelismo: raízes e fundamentos da troca política. Rio de Janeiro: Renovar, 2003.

BOURDIEU, P. O poder simbólico. Rio de Janeiro: Bertrand Brasil, 1996.

CHAGAS, M. A.; RABELO, B. V. Uma contribuição ao conhecimento da história de criação das Unidades de Conservação do Amapá - Amazônia Brasileira. Revista Sustentabilidade em Debate, Brasília, v. 6, n. 2, p. 211-227, 2015.

COLEMAM, J. Social Capital in the Creation of Human Capital. The American Journal of Sociology, v. 94, p. 95-120, 1988. Disponível em: https://faculty. washington.edu/matsueda/courses /587/readings/Coleman\%201988.pdf. Acesso em: 12 set. 2017. 
COSTA, F. A. Formação agropecuária da Amazônia. Os desafios do desenvolvimento sustentável. 2. ed. Belém: UFPA-NAEA, 2012.

DURSTON, J. ¿Qué es el capital social comunitário? Serie Políticas Sociales, n. 38, CEPAL: Santiago, 2000. Disponível em: https://repositorio.cepal.org/ bitstream/handle/11362/5969/1/S0007574_es.pdf. Acesso em: 01 set. 2017.

DURSTON, J. El capital social campesino en la gestíon del desarrollo rural: Diadas, equipos, puentes y escala. CEPAL: Santiago, 2002. Disponível em: https://repositorio.cepal.org/bitstream/handle/11362/2346/1/S2002033_ es.pdf. Acesso em 01 set. 2017.

DURSTON, J. Territorios divididos y resurgencia de capital social: dos casos de segregación étnica rural. REDES, Santa Cruz do Sul, v. 12, n. 1, p. 28-53, 2007. Disponível em: https://online.unisc.br/seer/index.php/redes/article/ view/106/64. Acesso em: 29 set. 2017.

ESPINOZA, V. Redes sociales en el manejo de situaciones de crisis familiar. In: Congresso Chileno de Antropologia, 3., Temuco, 1998. Anais [...]. Temuco: CCA, 1998. p. 1078-1089. Disponível em: https://www.aacademica.org/iii. congreso.chileno.de.antropologia/134.pdf. Acesso em: 29 set. 2017.

FILOCREÃO, A. S. M. Agroextrativismo e capitalismo na Amazônia: as transformações recentes no agroextrativismo do Sul do Amapá. 2014. 541f. Tese (Doutorado em Desenvolvimento Socioambiental) - Núcleo de Altos Estudos Amazônicos, Universidade Federal do Pará, Belém, 2007.

FILOCREÃO, A. S. M. A história do agroextrativismo na Amazônia amapaense. Macapá: UNIFAP, 2014.

GODBOUT, J. T. Introdução à dádiva. Revista Brasileira de Ciências Sociais, São Paulo, v. 13, n. 38, p. 39-51, 1998.

GRANOVETTER, M. Economic action and social structure: the problem of embeddedness. American Journal of Sociology, n. 91, p. 481-510, 1985.

MARTINS, J. S. O poder do atraso: ensaios de sociologia da história lenta. São Paulo: Hucitec, 1994.

MARTINS, P. H. De Lévi-Strauss a M.A.U.S.S. - Movimento Antiutilitarista nas Ciências Sociais: itinerários do dom. Revista Brasileira de Ciências Sociais, v. 23, n. 66. p. 105-130, fev. 2008.

MAUSS, M. Ensaio sobre a dádiva: introdução de Claude Levi-Strauss. Lisboa: Edições 70, 2001. 
MELUCCI, A. Accíon colectiva, vida cotidiana y democracia. México: El Colégio de México, 1999.

PORTES, A. Capital social: origens e aplicações na sociologia contemporânea. Revista Sociologia Problemas e Práticas, Lisboa, n. 33, p. 133-138, 2000.

RIBEIRO, A. C. Capital social e redes sociais no processo organizacional de comunidades agroextrativistas no Amapá. Tese. 293f. (Doutorado em Desenvolvimento Socioambiental) - Núcleo de Altos Estudos Amazônicos, Universidade Federal do Pará, Belém, 2008.

RIBEIRO, M. S. Natureza e mercado: castanheiros, empresários e as economias de suas relações. Tese. 290f. (Doutorado em Antropologia Social) - Faculdade de Filosofia, Letras e Ciências Humanas, Universidade de São Paulo, São Paulo, 2016.

ROBLES MORALES, J. M. Bajo el signo de la moral. ¿Son útiles los incentives morales para explicar la acción colectiva? Revista Internacional de Sociologia, Córdoba, v. 65, n. 46, p 185-204, 2007.

SABOURIN, E. Dádiva e reciprocidade nas sociedades rurais contemporâneas. Revista Tomo, n. 7, p. 75-104, 2004. Disponível em: https://seer.ufs.br/index. php/tomo/article/view/5244/4320. Acesso em: 03 out. 2017.

SABOURIN, E. Educação, dádiva e reciprocidade: reflexões preliminares. In: Jornal do Mauss Latino-Iberoamericano, ano 1, n. 4, 2008 a.

SABOURIN, E. Marcel Mauss: da dádiva à questão da reciprocidade. Revista Brasileira de Ciências Sociais, São Paulo, v. 23, n. 66, p. 131-138, fev. 2008b.

SANTOS, B. S.; MENESES, M. P. (org.). Epistemologias do Sul. São Paulo: Cortez, 2010.

SOUSA, W. P. A dinâmica dos sistemas de produção praticados em uma unidade de conservação de uso direto na Amazônia: a Reserva Extrativista do Rio Cajari no Estado do Amapá. 2006. 167f. Dissertação (Mestrado em Agriculturas Amazônicas) - Centro de Ciências Agrárias, Universidade Federal do Pará; Núcleo de Estudos Integrados sobre Agricultura Familiar, Empresa Brasileira de Pesquisa Agropecuária, Belém, 2006. 
